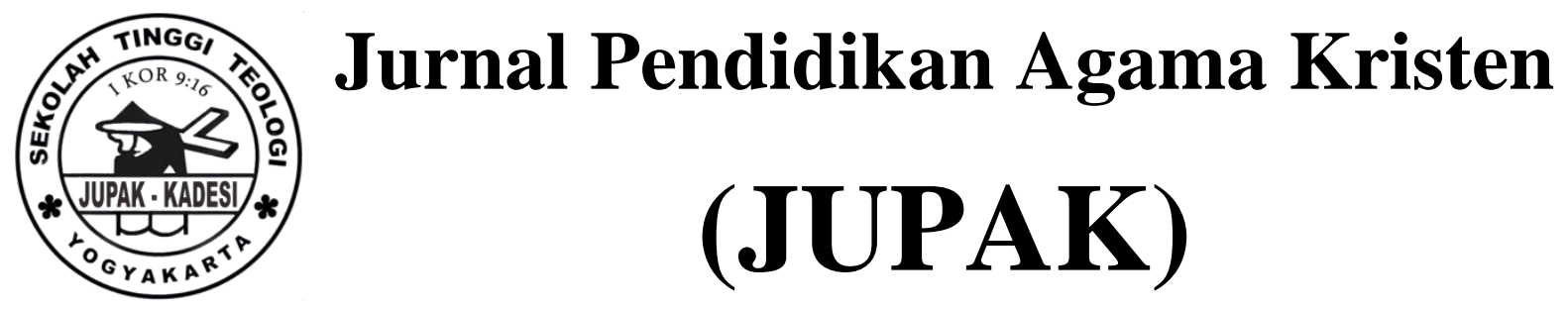

Vol. 1 No. 1 (December 2020) hlm. 23-42

Jurnal Pendidikan Agama Kristen (JUPAK)

e-ISSN 2774-3861

https://ejurnal.sttkadesiyogyakarta.ac.id/index.php/jupak

p-ISSN 2774-6399

https://doi.org/10.52489/jupak.v1i1.4

\title{
Implementasi Pengajaran Rasul Paulus tentang Nasehat Hidup Bersatu dan Merendahkan Diri Seperti Kristus Berdasarkan Filipi 2:1-30 Dikalangan Gembala Sidang GPdI Se- Jawa Tengah
}

\author{
Esra Sitanggang ${ }^{1)}$, Muner Daliman $^{2)}$, Hana Suparti ${ }^{3)}$, Sri Wahyuni ${ }^{4)}$ \\ Program Doktoral STT KADESI Yogyakarta, sitanggangesral@gmail.com
}

\section{Recommended Citation}

Turabian $8^{\text {th }}$ edition (full note)

Esra Sitanggang et al., "Implementasi Pengajaran Rasul Paulus Tentang Nasehat Hidup Bersatu Dan Merendahkan Diri Seperti Kristus Berdasarkan Filipi 2:1-30 Dikalangan Gembala Sidang GPdI Se-Jawa Tengah," Jurnal Pendidikan Agama Kristen (JUPAK) 1, no. 1 (2020): 1, accessed June 7, 2021, https://ejurnal.sttkadesiyogyakarta.ac.id/index.php/jupak/article/view/4.

American Psychological Association $7^{\text {th }}$ edition

(Sitanggang et al., 2020, p. 1)

Received: 27 November 2020

Accepted: 29 November 2020

Published: 04 December 2020

This Article is brought to you for free and open access by Sekolah Tinggi Teologi Kadesi Yogyakarta. It has been accepted for inclusion in Christian Perspectives in Education by an authorized editor of Jurnal Pendidikan Agama Kristen (JUPAK).

For more information, please contact juniorichson1995@gmail.com 


\begin{abstract}
The purpose of this study is to determine the level of implementation of the teaching of the Apostle Paul about the Advice to Live Together and Humble Yourself Like Christ Based on Philippians 2: 1-30 Among Pastors of the GPdI Council in Central Java. At the same time, the dominant dimensions and backgrounds determine the implementation of the Apostle Paul's Teaching among the Pastors of the GPdI Council in Central Java. The methodology used in this study is a quantitative method using a questionnaire and literature review. The literature contains the exegesis of Bible verses from Philippians 2: 1 - 30 which are contained in the dimension of advice to live together which is described in 9 supporting indicators and the dimension of advice to humble oneself like Christ which is explained in 8 supporting indicators. The results of this study indicate that: 1. The level of implementation of the Apostle Paul's Teaching on the Advice to Live One and Humble Yourself Like Christ Based on Philippians 2: 1-30 Among the Pastors of the GPdI Council in Central Java is in the high category; 2. The dominant dimension is to humble oneself like Christ (D2) and the dominant background is the number of congregations.
\end{abstract}

Keywords: Advice to Live Together, Humble

\begin{abstract}
Abstrak
Adapun tujuan dari penelitian ini adalah untuk mengetahui seberapa besar tingkat Implementasi Pengajaran Rasul Paulus Tentang Nasehat Hidup Bersatu Dan Merendahkan Diri Seperti Kristus Berdasarkan Filipi 2:1-30 Dikalangan Gembala Sidang GPdI Se- Jawa Tengah. Sekaligus dimensi dan latar belakang yang dominan menentukan Implementasi Pengajaran Rasul Paulus Tersebut dikalangan Gembala Sidang GPdI Se- Jawa Tengah.Metodologi yang digunakan dalam penelitian ini adalah metode kuantitatif dengan menggunakan angket kuesioner dan kajian literatur. Adapun literatur memuat eksegesa ayat Alkitab dari Filipi $2: 1$ - 30 yang termuat dari dimensi nasehat hidup bersatu yang dijelaskan dalam 9 indikator pendukung serta dimensi nasehat merendahkan diri seperti Kristus yang dijelaskan dalam 8 indikator pendukung. Hasil penelitian ini memperlihatkan bahwa: 1 . Tingkat implementasi Pengajaran Rasul Paulus Tentang Nasehat Hidup Bersatu Dan Merendahkan Diri Seperti Kristus Berdasarkan Filipi 2:1-30 Dikalangan Gembala Sidang GPdI Se- Jawa Tengah pada kategori tinggi.; 2. Dimensi yang dominan adalah merendahkan diri seperti Kristus (D2) dan latar belakang yang dominan adalah jumlah jemaat.
\end{abstract}

Kata Kunci : Hidup Bersatu, Merendahkan diri

\title{
PENDAHULUAN
}

Hidup bersatu merupakan kalimat yang sudah sering terdengar dalam kehidupan masyarakat, bukan hanya dikalangan gereja, sekolah, bahkan kehidupan masyarakat yang terdiri dari berbagai tingkat usia, pendidikan bahkan ekonomi, sosial dan budaya. Mengingat kesatuan adalah modal dasar sebuah organisasi dapat hidup, bertumbuh dan berkembang dengan baik mencapai tujuannya dengan maksimal. 
Terlebih bagi gereja Tuhan dengan adanya bermacam - macam denominasi dan doktrin yang sesungguhnya bisa menjadi kekayaan Kristus tetapi tidak jarang terjadi gesekan - gesekan yang mengakibatkan perselisihan.Seharusnya setiap gereja memahami bahwa walaupun dalam perbedaan sinode / denominasi tetapi mereka tetap diikat menjadi satu dalam tubuh Kristus maka mereka. Seperti yang disampaikan Yusuf Roni dalam bukunya menyebutkan "Gereja dapat dijuluki sebagai Tubuh Kristus karena anggota Tubuh Kristus dipersatukan dengan Kristus dalam keselamatan"(Roni, 1993). Dimana setiap anggota Tubuh Kristus mengikuti Kristus sebagai Pemimpin (Kepala) gereja. Anggota Tubuh Kristus juga merupakan perwakilan jasmani Kristus di dunia ini . Walter Mond menegaskan bahwa : "Semua orang percaya adalah anak-anak Allah karena iman di dalam Kristus Yesus dan menjadi bagian dalam anggota tubuh Kristus" (Tingginehe, 2003).

Salah satu dari sekian banyak denominasi tersebut adalah gereja Pantekosta di Indonesia (GPdI) yang merupakan salah satu lembaga Gereja Kristen di Indonesia yang mempercayai Allah yang Esa, atau Allah Tri-Tunggal. Penggunaan nama GPdI merupakan sebagai pengganti nama Vereeniging De Pinkstergemeente in Nederlandsch Oost Indie (Turangan, 2018). Organisasi GPdI memiliki sifat yang sangat unik dan sulit dipahami melalui kacamata awam. Adapun sifat-sifat unik yang telah melekat tersebut yaitu: Faktor Paternalistis (sangat mengutamakan/menghargai orang tua/senioritas dalam kepemimpinan), Pendekatannya lebih bersifat kekeluargaan/persuasif., kombinasi organisasi dan organisme.,dan Faktor profesionalisme tidak menjadi utama. Kondisi-kondisi seperti inilah yang mengharuskan seorang pemimpin GPdI di dalam segala strata, tidak cukup hanya mengandalkan "skill" saja dalam menggembalakan tetapi juga memerlukan "seni" untuk memimpin.

Karena modelnya yang fleksibel membuat GPdI berkembang begitu cepat dan menjadi salah satu gereja dengan jumlah terbanyak di Indonesia. Tercatat sampai hari ini terdapat lebih dari 11.000 gereja GPdI dengan jumlah jiwa mencapai 3-4 Juta orang jemaat Pantekosta yang tersebar di berbagai pelosok Indonesia mulai dari desa-desa, kota-kota, dusun-dusun, lembah-lembah, pegunungan pulau-pulau dari Sabang sampai Merauke dari pulau Miangas sampai pulau Rote. Sedangkan di Jawa Tengah sendiri setidaknya sudah ada 721 gereja GPdI.Jumlah yang tidak sedikit dan membutuhkan sentuhan khusus dalam mengayomi sekaligus mempersatukan gereja ini.

Untuk itulah sebagai dasar pengkajian teori diambil dari Filipi 2:1-30 tentang nasehat Rasul Paulus kepada jemaat di Filipi untuk hidup bersatu dan merendahkan diri seperti 
Kristus karena itu adalah modal dasar membangun tubuh Kristus secara holistik. Karena Paulus khawatir apabila dibiarkan maka gereja Filipi berada dalam ambang perpecahan (Flp. 2:1-5). Selain itu juga ada ancaman dari luar yang membuat jemaat Filipi merasa lemah adalah jemaat mendapatkan tantangan karena Injil (Flp. 1:29-30),yaitu adanya pengaruh dunia yang hendak mengombang-ambingkan iman dan ketaatan mereka (Flp. 2:12-16)melalui pengajar-pengajar sesat (Flp. 3:1-2) serta pada saat itu banyak orang yang hidup sebagai seteru salib (Flp. 3:18). Oleh sebab itu untuk mencegah terjadinya perpecahan dalam jemaat di Filipi dalam Filipi pasal 2 Rasul Paulus mengirimkan Timotius anak rohaninya untuk meneguhkan iman jemaat di Filipi yang terombang - ambing serta menjadi wakil dari Paulus yang pada saat itu dipenjara.

Berdasarkan Filipi 2:1-30 Rasul Paulus menasehatkan bagi para gembala agar memahami pentingnya mewujudkan hidup bersatu. Hal ini dapat terwujud jika setiap gembala sehati sepikir, ada satu roh, ada satu jiwa, ada satu tujuan, rendah hati, memperhatikan kepentingan orang lain, dan menaruh pikiran yang terdapat di dalam Kristus. Berbagai hal dapat timbul dalam organisasi GPdI terlebih dikarenakan sinode menganut sistem otonomi.Maksudnya adalah setiap gereja berhak mengatur rumah tangganya masing masing tetapi masih ada kewajiban - kewajiban yang harus ditaati yang diatur dalam anggaran dasar dan anggaran rumah tangga GPdI. Sistem otonomi tersebut mengakibatkan terkadang muncul gesekan - gesekan dikarenakan masih ada gembala bersifat eksklusif dan tertutup terhadap organisasi mengingat jumlah gereja GPdI yang banyak serta tersebar di berbagai tempat. Gembala tersebut hanya memikirkan gerejanya sendiri dengan membangun gerejanya tanpa memperhatikan gereja yang lain, selain itu juga ada pandangan bahwa gerejanya lebih suci atau memiliki kasta / tingkatan lebih tinggi dari gereja lain sehingga mereka tidak mudah bergaul dengan sembarangan gembala sidang mereka hanya bergaul dengan orang - orang sesinodenya saja. Dari wawancara dengan beberapa pendeta beberapa gembala sangat setuju, jikalau faktor ekonomi sangat mempengaruhi gembala-gembala untuk hidup bersatu, gembala yang sudah mapan secara finasial biasanya lebih tertutup terhadap gembala lain, mereka biasanya lebih fokus kepada semua kegiatan, program dan usaha untuk meningkatkan pertumbuhan gerejanya sendiri.Gembala - gembala yang ekslusif tersebut sesungguhnya belum memahami panggilannya dalam gereja yang universal.Biasanya gembala yang bersifat esklusif tersebut karena kesibukannya dalam pelayanan atau berfokus pada gerejanya sendiri menyebabkan gembala tersebut jarang menghadiri pertemuan pertemuan MD wilayah setiap bulan dengan alasan padatnya kegiatan pelayanan jemaat. 


\section{Esra Sitanggang, Muner Daliman, Hana Suparti, Sri Wahyuni}

Padahal Yakob Tomatala dalam bukunya menyatakan : "Gembala atau pemimpin Kristen bukan dipanggil untuk menduduki suatu posisi atau jabatan duniawi tetapi ia dipanggil untuk melaksanakan tugas dan tanggung jawab sebagai pelayan/ hamba Allah" (Tomatala, 2002). Hal tersebut mengindikasikan bahwa gembala- gembala tersebut kurang memahami Nasehat Paulus berdasarkan Filipi 2:1-30 yang pertama yaitu nasehat hidup bersatu.

Berdasarkan Filipi 2:1-30 hal yang kedua Rasul Paulus menasehatkan para gembala agar merendahkan diri seperti Kristus. Hal ini dapat terwujud jika setiap gembala meneladani Yesus dengan menjadi hamba, taat melakukan pelayanannya serta didasari dengan ketulusan. Gembala juga harus tetap teguh berpegang dalam firman Tuhan, saling menolong dan melayani dalam pelayanan Injil sekaligus gembala harus mau berkorban untuk pelayanan Injil. Jika setiap gembala mempraktekan hal - hal tersebut maka akan terjalin suatu keadaan organisasi yang damai serta mengalami pertumbuhan pelayanan yang maksimal. Tetapi terkadang masih ditemui gembala yang apatis terhadap gembala yang lain terutama bagi gembala yang menggembalakan jemaat yang terbilang banyak. Seakan meremehkan gembala perintisan yang hanya beberapa orang.Terkadang usul - usul mereka tidak didengarkan dan menganggap sebelah mata.Hal ini terjadi karena gembala tersebut masih kurang sadar bahwa mereka sebenarnya saling membutuhkan.Gembala - gembala yang demikian terkadang lupa bahwa mereka adalah bagian dari tubuh Kristus yang di dalamnya tersusun dari organ tubuh yang saling melengkapi.Tanpa ada sinergitas maka fungsi tubuh pasti tidak sempurna.Tubuh tidak bisa berlari kalau tanpa kaki. Tubuh tidak bisa bekerja dengan baik kalau mata tidak mau terbuka.Oleh karena itu, sekalipun ada anggota tubuh sangat kecil fungsinya, tetapi tidak boleh diremehkan oleh anggota lainnya.Namun juga masih ada gembala sidang yang kurang memahami bahwa mereka saling membutuhkan. Hal ini terjadi karena gembala tersebut tidak mau merendahkan dirinya sama seperti Kristus menganggap orang lain lebih utama tetapi justru menganggap dirinya lebih utama dari pada gembala yang lain apalagi yang secara ekonomi dibawah mereka. Hal demikian mengindikasikan bahwa masih ada gembala yang memikirkan dan berfokus pada hal duniawi. Sehingga terindikasi bahwa gembala tersebut kurang memahami nasehat Paulus dalam Filipi 2:1-30 dalam nasehat merendahkan diri seperti Kristus.

\section{METODOLOGI}

Metode dan rancangan penelitian yang akan digunakan dalam penelitian ini adalah: menggunakan rancangan penelitian kuantitatif dengan metode angket kuesioner .Penelitian 
kuantitatif adalah penyelidikan dengan menggunakan ilmiah, yaitu prosedur langkah-langkah dalam memecahkan masalah atas dasar pengamatan empiris (Creswell, 2015). Adapun tempat penelitiannya adalah di gembala-gembala sidang Gereja Pantekosta di Indonesia Se Jawa Tengah, yaitu meliputi enam belas (16) wilayah.

Tabel 1 Daftar Wilayah

\begin{tabular}{|c|c|}
\hline Wilayah & Daerah \\
\hline I & Kota Kabupaten Semarang, Karang Jati \\
\hline II & Kab. Batang, Kota dan Kab. Pemalang \\
\hline III & Pemalang, Tegal dan Brebes \\
\hline $\mathrm{V}$ & $\begin{array}{l}\text { Kab. Banjar Negara,Kota } \\
\text { Purwokerto,Kab. Banyumas }\end{array}$ \\
\hline VI & Kab. Temanggung, Kab. Wonosobo \\
\hline VII & Kota\& Kab. Magelang, Kab. Purworejo \\
\hline VIII & $\begin{array}{l}\text { Kota Salatiga, Kec. Getasan dan Kec. } \\
\text { Ambarawa, Kec. Bandungan. }\end{array}$ \\
\hline IX & $\begin{array}{l}\text { Kab. Boyolali, Kab. Semarang bagian } \\
\text { selatan }\end{array}$ \\
\hline $\mathrm{X}$ & Kec. Delanggu, Kab.Klaten, \\
\hline XI & $\begin{array}{l}\text { Kab.Solo, Kec. Kartasura, Kec.Gatak, } \\
\text { Kec.Colomadu, , }\end{array}$ \\
\hline XII & Karanganyar, Sragen \\
\hline XIII & $\begin{array}{l}\text { Kab. Wonogiri, Kab Sukoharjo, } \\
\text { (sebagian) }\end{array}$ \\
\hline XIV & $\begin{array}{l}\text { Kab.Demak,Kab. Kudus, Kab. Jepara, } \\
\text { Kab Pati }\end{array}$ \\
\hline $\mathrm{XV}$ & Kab. Grobogan, Purwodadi \\
\hline XVI & Kab. Blora, Kab. Rembang,Kec. Cepu \\
\hline
\end{tabular}

Adapun waktu pelaksanaa penelitian ini akan dilaksanakan Juni 2019 sampai bulan Juni 2020.

Populasi dalam penelitian ini adalah seluruh Gembala Sidang GPdI Se Jawa Tengah berjumlah 721 orang.Adapun pengambilan jumlah sampel dengan rumus dari Isaac dan Michael dengan taraf kesalahan 5\% (Ferdinand, 2011). Maka jumlah sampel penelitian yang diambil adalah sebanyak 235 orang. Dengan pembagian 30 orang gembala sebagai sampel uji coba, dan 205 sebagai sampel final. 
Pada penelitian ini yang menjadi endogenous variabel (Y) adalah Pengajaran Rasul Paulus Tentang Nasehat Hidup Bersatu Dan Merendahkan Diri Seperti Kristus Berdasarkan Filipi 2:1-30 ; dan sebagai exogenous variabel (D1) Tentang Nasehat Hidup Bersatu Berdasarkan Filipi 2:1- 30 yang memiliki 9 indikator yaitu : sehati sepikir, satu kasih, satu jiwa, satu tujuan , mengutamakan kepentingan orang lain, menaruh pikiran dalam Kristus.; (D2) Nasehat Merendahkan Diri Seperti Kristus Berdasarkan Filipi 2:1-30. Memiliki 8 indikator seorang hamba, taat, melakukan pelayanan dengan tulus, berpegang pada firman kebenaran, saling melayani, dan rela berkoban dalam pelayanan. Selain itu juga terdapat 5 moderator Variabel latar belakang responden diantaranya : Jenis Kelamin, Status Pernikahan, Pendidikan, Usia, Jumlah Jemaat.

\section{KAJIAN TEORI}

\section{Nasehat Hidup Bersatu Dan Merendahkan Diri Seperti Kristus Berdasarkan}

\section{Filipi 2:1-30}

Ada banyak jemaat yang Paulus dirikan dalam pelayanan misinya. Paulus mendirikan sebuah jemaat sekitar tahun 49-50 M. Salah satunya adalah jemaat Filipi yang didirikan Paulus sekitar tahun 51 masehi (Kis. 16:13-40, 1 Tes. 2:2) yang mayoritas jemaatnya adalah orang-orang Kristen yang berasal dari kalangan orang kafir / penyembah berhala . Paulus bangga kepada mereka, sehingga Paulus selalu mengucap syukur kepada Allah setiap kali berdoa untuk mereka (Flp. 1:1-8). Mereka adalah jemaat yang setia dan semangat (Duyverman, 1983). Hal ini dibuktikan dengan kesediaan jemaat Filipi untuk mendukung Paulus secara finansial melalui pelayanan Epafroditus. Yang menjadi salah satu tujuan Paulus menuliskan surat Filipi ini adalah adanya ajaran-ajaran palsu yang mempengaruhi jemaat. Ajaran tersebut seperti ajaran Gnostik yang menolak parousia (Flp. 3:20-21) dan kebangkitan masa depan (Flp. 3:10). Mereka juga tidak menunjukkan kesungguhan dalam berperilaku etis (Flp. 3:15-16) karena mereka lebih bersifat libertinis (serba ingin bebas) (Flp. 3:19) dan sikap yang terlalu mengagung-agungkan kesempurnaan tetapi hanya sebatas lahiriah (Marxen, 1996).

Secara spesifik pada pasal 2 Paulus menasehatkan jemaat di Filipi agar mereka tetap bersatu ditengah perpecahan pikiran yang terjadi karena munculnya sekte - sekte atau ajaran sesat yang berkembang dalam jemaat.Paulus menasehatkan agar mereka tetap hidup di dalam Kristus. Karena di dalam Kristus mereka akan menemukan nasehat yang menuntun hidup mereka dalam kebenaran, ada penghiburan dalam berbagai situasi, ada persekutuan dalam 
Roh, ada kasih mesra yang menyatukan dan menghendaki jemaat agar memiliki kesehatian, mereka harus sepikir, satu jiwa dan tetap satu tujuan yaitu Kristus.

\section{Nasehat Hidup Bersatu}

Paulus menganggap perlu menasehati jemaat Tuhan yang ada di kota Filipi, mengingat rentannya perpecahan diantara mereka. Ancaman Bahaya perpecahan yang mungkin bisa terjadi, yaitu oleh karena beberapa diantara jemaat merasa bahwa mereka adalah jemaat yang berusaha sungguh-sungguh dan mereka berusaha unuk menumbuhkan kerohanian mereka, selanjutnya Barclay mengatakan: "Ketika orang dalam keadaan yang sungguh-sungguh dan keyakinan mereka benar-benar penting bagi mereka, maka mereka cenderung bangkit saling melawan, makin besar semangat merka makin besar pula bahaya mereka akan saling bentrok (Wiliam Barclay, 2002). Untuk menghindari kejadian ini, maka Paulus menasehati jemaat Tuhan yang ada di Kota Filipi untuk tetap hidup bersatu dalam perbedaan.

Jemaat Kristus sendiri sering disebut oleh Paulus sebagai Tubuh Kristus karena dalam perbedaan mereka tetapi merupakan satu kesatuan yang tidak terpisahkan dan saling membutuhkan (Roni, 1993). Pandangan sekilas tentang apa yang kebanyakan orang pikirkan mengenai kata "jemaat" menunjukkan bahwa mayoritas besar orang menggunakan kata ini untuk menyebutkan sebuah bangunan gereja di mana dilangsungkan berbagai upacara keagamaan atau sebagai bagian dari nama beragam denominasi gereja.

Oleh sebab itu sama seperti Jemaat Filipi adalah jemaat yang heterogen. Ada banyak suku bangsa di jemaatitu berarti juga ada perbedaan latar belakang, perbedaan budaya,karater, pola pikir dan sebagainya. Adanya berbagai perbedaan itu rawan menimbulkan konflik, pertentangan dan pertengkaran di antara sesama anggota jemaat. Dalam keadaan yang demikian, jemaat Filipi dapat mewujudkan kesatuan sebagai umat Tuhan dan persekutuan yang baik di antara sesama anggota jemaat. Sekalipun banyak perbedaan asal ada kasih,jemaat Filipi dapat mewujudkan kesatuan dan persekutuan yang indah. Karena itu,dengan memiliki satu kasih akan mempersatukan dan menyempurnakan. Sugiyanto berpendapat :

Ungkapan kasih itu mempersatukan dan menyempurnakan, mengandung arti bahwa kasih itu mempunyai kekuatan yang luar biasa, yaitu kekuatan yang memampukan kita untuk membuang segala sifat buruk kita dan memampukan kita untuk mewujudkan kesatuan dan persekutuan yang indah dalam jemaat. Bukan berarti kalau ada kasih maka tiada perbedaan, perbedaan tetap ada tetapi kasih membuat masing-masing anggota jemaat dapat menerima perbedaan itu. Adanya kasih bukan berarti tidak ada pertengkaran, pertengkaran tetap saja bisa terjadi di antara sesama anggota keluarga, 
tetapi kasih membawa setiap anggota keluarga untuk dapat saling memafkan sehingga terwujud perdamaian (Wiryoputro, 2008).

Rasul Paulus memberikan pengajaran agar gereja menggunakan setiap fungsi kasih Yesus secara menyeluruh sehingga kasih Yesus yang akan bekerja untuk menyatukan dan menyempurnakan setiap pelayanan jemaat. Dengan pemahaman teologis yang tepat inilah baru dapat kita pahami ungkapan dari Paulus tentang kedekatan hubungan Kristus dengan jemaat yaitu melalui kasih. Paulus sekaligus menegaskan hubungan Kristus dengan jemaat dan kedudukan serta fungsi Gereja seharusnya sebagai wujud kesatuan kasih (Sidharta, 2019).

\section{Nasehat merendahkan diri seperti Kristus}

Rendah diri merupakan suatu perasaan atau keadaan dimana seseorang merasa lebih rendah dibanding orang lain dalam satu atau lain hal (Chaniago, 2002). Perasaan demikian dapat muncul sebagai akibat sesuatu yang nyata / fakta atau hanya perasaan imajenasi diri saja. Tetapi kata merendahkan diri lebih kepada situasi / keadaan yang sengaja dibuat agar keadaannya lebih rendah dari orang lain. Tetapi kata yang dipakai dalam ayat ini adalah 'etapeinosen" yang pendekatannya bukan lebih kepada perasaan minder tetapi perasaan ketidak berdayaan dalam situasi paling rendah/ ia telah merendahkan, membungkuk (Lexicon, no date).

Jika mengacu kepada Alkitab Perjanjian Baru, akan banyak menemukan kalimatkalimat yang merekomendasikan tentang kerendahan diri yang dimaksud, seperti yang ditulis oleh Injil Matius.23:12;Lukas 14:11; 18:14). Kerendahan diri tersebut mengandung unsur ketaatan dan penyangkalan diri yang merupakan ciri yang khas dari kepribadian Yesus yang luar biasa, maka itu juga yang seharusnya menjadi ciri khas orang Kristen. Sifat mementingkan diri sendiri akan merusak tatanan keserupaan manusia dengan Kristus, dimana sesungguhnya itulah yang menjadi ciri khas orang Kristen atau orang percaya.

Kata telah mengosongkan diri-Nya. Ekenosen bukan dimaksudkan sebagai kiasan (yaitu, bahwa Dia membuang semua sifat ilahi-Nya), tetapi sebuah "ungkapan yang jelas tentang penyangkalan diri-Nya yang mutlak" (Wijaya, 2019). Sikap Tuhan Yesus yang merendahkan diri sedemikian rupa itu ,dinyatakan oleh Donald S. Whitney sebagai Hamba yang sempurna. Hamba yang sempurna ditunjukkan dengan kesediaan-Nya melakukan segala sesuatu guna memenuhi tugas yang dipercayakan kepada-Nya (Whitney, 1994). Lebih lanjut whitney mengatakan bahwa kerelaan Yesus untuk melepaskan haknya juga dapat dilihat dari 
kelahiran-Nya yang menunjukkan kepapaan atau kehinaan-Nya yang sangat ekstrim. Ia tidak dilahirkan dalam istana atau rumah yang layak, tetapi Ia lahir di tempat sederhana, sangat besar kemungkinan di kandang hewan (Lukas 2:7) .

Wiliam Barclay berpendapat, "Berbicara tentang Yesus yang telah merendahkan diriNya sendiri dan taat sampai mati, bahkan sampai mati dikayu salib. Ciri khas utama hidup Yesus ialah kerendahan hati, ketaatan, dana penyangkalan diri, Ia tidak mau menguasai manusia, tetapi hanya melayani mereka; Ia tidak menginginkan kehendak-Nya sendiri, tetapi kehendak Allah, Ia tidak ingin meninggikan diri, tetapi menyangkal seluruh kemuliaan-Nya demi manusia”.(Wiliam Barclay, 2002) “ karena pemimpin yang berhasil adalah pemimpin yang mampu mengadaptasikan gaya agar sesuai dengan situasi tersebut"(Thoha, 2007). Yesus menempatkan diri pada situasi terendah agar setiap orang dapat terjangkau oleh dimensi kasih karunia Allah.Demikian juga gembala sebagai hamba Tuhan harus bisa menempatkan diri sebaik - baiknya bukan sebagai orang yang ingin mendapatkan prioritas ekstra untuk dilayani tetapi harus menjadi pelayan bagi jemaat - jemaatnya.oleh sebab itu setiap gembala harus meneladani konsep kerendah dirian Kristus ini.

Suatu kontradiksi yang nyatabagi dunia yang mencari gelar, ketenaran, nama hebat agar menjadi orang terpandang, terkemuka tetapi justru Yesus mengajarkan hal yang sebaliknya. Model pelayanan hamba tidak hanya berbicara tentang definisi atau teori, namun juga harus dapat dipraktekkan. Karena pelayanan hamba diprakarsai karena Yesus dan diteruskan oleh para pengikut-Nya, maka sangatlah berfaedah apabila kepemimpinan yang melayani diterapkan oleh pemimpin Kristen dalam gereja dan masyarakat.

Pelayanan hamba membuat Yesus leluasa untuk terjun langsung melayani kedalam masyarakat majemuk, hal ini biasa disebut dengan blusukan. Dengan blusukan, masyarakat dapat menyaksikan secara langsung bagaimana pemimpin melayani masyarakat. Seperti yang Yesus lakukan ketika Yesus mengunjungi banyak daerah di Israel. Cara ini adalah yang paling menonjol, karena blusukan disaksikan oleh masyarakat itu sendiri. Karena dengan melakukan blusukan ini pemimpin bisa tahu seperti apa masyarakat yang dipimpinnya, sehingga menghasilkan efektifitas pelayanannya (Greenleaf, 2019). Yesus menjangkau kaum - kaum marjinal yang terpinggirkan serta tidak dipandang oleh pemerintah mereka adalah golongan - golongan proselit. Pelayan hamba adalah sebuah unsur yang sangat mewarnai kepemimpinan Yesus. Bahkan dapat dikatakan bahwa pelayanan hamba adalah jiwa dari kepemimpinan rohani yang Yesus ajarkan kepada anak-anak-Nya. Charles R. Swindoll, 
dalam bukunya Improving Your Serve: The Art of Unselfish Living, menulis sebagai berikut. "Ia datang untuk melayani dan member (Charles Swindoll, 2005).

Karena secara sadar pekerjaan pelayanan Injil bukanlah pekerjaan yang mudah, namun bukan berarti pekerjaan yang sulit, karena pemberitaan injil bukan merupakan suatu tantangan, melainkan suatu perintah. Amanat Agung ini merupakan suatu tanggung jawab yang harus dipikul. Oleh sebab iti pekerjaan pelayan Tuhan membutuhkan kerja sama yang baik, baik antara pelayan injil maupun orang percaya, sebagian umat Tuhan yang ada di kota Filipi sangat antusias menolong pekerjaan Tuhan yang dilakukan oleh Paulus, Timotius, bahaka Epafras, Paulus berkata ia sangat puas dengan pengertian dan perhatian umat Tuhan yang ada di kota Filipi. Paulus juga memuji kerja sama yang telah dilakukan oleh umat Tuhan yang ada di kota Filipi (Fil. 4:10-20).

Menjadi realita bahwa perlu sinergitas dalam memberitakan Injil harus dipahami oleh setiap gembala - gembala sidang. Mereka tidak dapat melangkah sendiri perlu dukungan organisasi, dukungan gembala lain agar program pemberitaan Injil dapat berjalan dengan baik. Terkadang sikap egois yang mengakibatkan gembala - gembala tidak melibatkan instrumen lain padahal dengan melibatkan instrumen lain akan memperkuat ujung tombak penginjilan dan efektifitas metode dapat di beritakan. GPdI terkenal dengan sekolah penginjilan dengan pembekalan 6 bulan bagi calon gembala - gembala untuk dapat terjun ke ladang misi tetapi sebenarnya modal tersebut masih kurang. Pendalaman Teologi dan misi yang kurang dalam akan menyebabkan kurang efektifnya program penginjilan oleh sebab itu sama seperti Paulus mengutus Timotius gembala harus didampingi oleh seorang mentor agar penginjilan dapat berjalan dengan maksimal.

Paulus menyadari bahwa dalam pekerjaannya memberitakan Injil penuh tantangan dan tekanan oleh sebab itu dia sampai masuk ke dalam penjara sebagai konsekuensinya memberitakan Injil Kristus.Sama halnya yang dialami oleh Epafroditus sampai hampir mati.Rela berkorban dalam pelayanan bukanlah perkara yang mudah tetapi sekaligus juga bukan sesuatu yang sulit untuk dilakukan. Modalnya cuma satu yakni hati. Yesus mengajarkan kepemimpinan hamba dan melayani, pada intinya, terpusat pada apa yang ada di dalam hati seorang pemimpin. Hati akan menentukan apa yang terlihat keluar. Melaui hati, seorang pemimpin akan dapat mementingkan orang lain daripada dirinya sendiri (Zaluchu, 2010) 


\section{HASIL DAN PEMBAHASAN}

Setelah istrumen diuji validitas isi dan konstruk melalui kalibrasi istrumen maka instrumen dibagikan kepada 235 orang responden yang terdiri 30 angket uji coba dan 205 angket final dan setelah data terkumpul dilakukan analisa data yaitu terdiri dari : deskripsi statistik, uji analisis prasyarat (normalitas, linieritas, homogenitas) baru dilakukan uji hipotesis sesuai dengan teknik analisis data yang ditetapkan.

Pertama, pengujian hipotesis pertama yang diajukan, yakni Tingkat Implementasi Pengajaran Paulus tentang Nasehat Hidup Bersatu Dan Merendahkan Diri Seperti Kristus Berdasarkan Filipi 2 : 1-30 Di Kalangan Gembala Sidang GPdI Se Jawa Tengahberada dalam kategori "Rendah". Dari hasil perhitungan statistik yang dilakukan dengan Confidence Interval pada taraf signifikansi 5\% diperoleh nilai lower Bound 262.7544 dan upper Bound 268.1919 sehingga dapat disimpulkan bahwa tingkat Implementasi Pengajaran Paulus tentang Nasehat Hidup Bersatu Dan Merendahkan Diri Seperti Kristus Berdasarkan Filipi 2 : 1-30 Di Kalangan Gembala Sidang GPdI Se Jawa Tengah ( Y ) ada pada kategori “ Tinggi “. Hal itu didukung oleh Kesimpulan yang diambil atas hipotesis pertama dibandingkan dengan hasil perhitungan terhadap setiap dimensi ( D1 - D2 ) sebagai exogenous variabel yang memperlihatkan kecenderungan yang lebih spesifik terhadap endogenous Variable yang sama - sama menyatakan tingkat implementasi dalam kriteria " Tinggi " atau dengan kata lain bahwa tingkat Implementasi Pengajaran Paulus tentang Nasehat Hidup Bersatu Dan Merendahkan Diri Seperti Kristus Berdasarkan Filipi 2 : 1-30 Di Kalangan Gembala Sidang GPdI Se Jawa Tengah ( Y ) terimplementasi secara signifikan pada $\alpha<0,05$.

Tabel 2

Rekapitulasi hasil uji hipotesis pertama tentang kecenderungan Implementasi Pengajaran Paulus tentang Nasehat Hidup Bersatu Dan Merendahkan Diri Seperti Kristus Berdasarkan Filipi 2 : 1-30 Di Kalangan Gembala Sidang GPdI Se Jawa Tengah (Y )

\begin{tabular}{|c|l|l|}
\hline No. & \multicolumn{1}{|c|}{ Variabel } & Hasil Penelitian \\
\hline \multirow{1}{*}{1} & Implementasi & \\
& Pengajaran Paulus & Implementasi \\
& tentang Nasehat Hidup & pada kategori " \\
& Bersatu Dan & Tinggi" \\
& Merendahkan Diri & \\
& Seperti Kristus & \\
\hline
\end{tabular}




\begin{tabular}{|l|l|l|}
\multirow{2}{*}{2} & $\begin{array}{l}\text { Berdasarkan Filipi 2: 1- } \\
\text { 30 Di Kalangan } \\
\text { Gembala Sidang GPdI } \\
\text { Se Jawa Tengah ( Y) }\end{array}$ & \\
\hline \multirow{2}{*}{3} & $\begin{array}{l}\text { Implementasi Dimensi } \\
\text { Nasehat Hidup Bersatu } \\
(\text { D1) }\end{array}$ & $\begin{array}{l}\text { Implementasi } \\
\text { pada kategori " } \\
\text { Tinggi" }\end{array}$ \\
\hline \multirow{2}{*}{$\begin{array}{l}\text { Implementasi Dimensi } \\
\text { Nasehat Merendahkan } \\
\text { Diri Seperti Kristus (D2) }\end{array}$} & $\begin{array}{l}\text { Implementasi } \\
\text { pada kategori " } \\
\text { Tinggi " }\end{array}$ \\
\hline
\end{tabular}

Dari tabel tersebut sehingga dapat disimpulkan bahwa hipotesis pertama yang diajukan Tingkat Implementasi Pengajaran Paulus tentang Nasehat Hidup Bersatu Dan Merendahkan Diri Seperti Kristus Berdasarkan Filipi 2 : 1-30 Di Kalangan Gembala Sidang GPdI Se Jawa Tengahberada dalam kategori "Rendah" tenyata ditolak

Dari hasil diatas menunjukan bahwa dugaan peneliti salah yang menilai bahwa Tingkat Implementasi Pengajaran Paulus tentang Nasehat Hidup Bersatu Dan Merendahkan Diri Seperti Kristus Berdasarkan Filipi 2 : 1-30 Di Kalangan Gembala Sidang GPdI Se Jawa Tengahmenurut berada dalam kategori "Rendah" tetapi ternyata pada kategori Tinggi maka dapat disimpulkan bahwa secara garis besar Gembala Sidang GPdI Se Jawa Tengah sudah mengimplementasikan Pengajaran Paulus tentang Nasehat Hidup Bersatu Dan Merendahkan Diri Seperti Kristus Berdasarkan Filipi 2 : 1-30 dengan baik.

Kedua, Pengujian atas hipotesis kedua yaitu : Dimensi yang paling dominan yang menentukan implementasi pengajaran rasul Paulus tentang nasehat untuk bersatu dan merendahkan diri seperti Kristus Berdasarkan Filipi 2 : 1 -30 di Kalangan Gembala Gembala Sidang Gereja Pantekosta di Indonesia ( GPdI ) Se - Jawa Tengahadalah Nasehat merendahkan diri seperti Kristus (D2). dari hasil analisis menggunakan Regresi linier yang menyatakan Dimensi Nasehat merendahkan diri seperti Kristus (D2)memiliki nilai determinasi tertinggi yaitu 0,955 dengan kontribusi terhadap endogenous variabel sebesar $92,1 \%$. 
Tabel 2

Rekapitulasi asosiasi dan kontribusi exogenous variabel terhadap endogenous variabel

\begin{tabular}{|c|l|c|c|c|}
\hline No & \multicolumn{1}{|c|}{ Dimensi } & $\mathrm{r}$ & $\begin{array}{c}\mathrm{r} \\
\text { square }\end{array}$ & Kontribusi \\
\hline 1 & $\begin{array}{l}\text { Nasehat } \\
\text { Hidup } \\
\text { Bersatu (D1) }\end{array}$ & 0,948 & 0,898 & $89,8 \quad \%$ \\
\hline 2 & $\begin{array}{l}\text { Nasehat } \\
\text { Merendahkan } \\
\text { Diri Seperti }\end{array}$ & 0,955 & 0,912 & \\
\hline
\end{tabular}

Hasil tersebut di konfirmasi dengan pengujian antara exogenous variable secara bersama - sama terhadap endogenous variablemelalui analisis Binersegmentation yang disebut dengan Classification and regression Trees (CRT) dengan menetapkan prunning yaitu depth sebesar 3 ; Parent sebesar 2 ; dan Child sebesar 1, pada taraf signifikansi 0,05. Dari hasil analisis antara exogenous variable secara bersama - sama terhadap endogenous variable menunjukan bahwa Dimensi Nasehat Merendahkan Diri Seperti Kristus (D2) menjadi Dimensi paling dominan membentuk Implementasi Pengajaran Paulus tentang Nasehat Hidup Bersatu Dan Merendahkan Diri Seperti Kristus Berdasarkan Filipi 2 : 1-30 Di Kalangan Gembala Sidang GPdI Se Jawa Tengah ( Y ) karena berada dipuncak pohon regresi dan dari hasil CRT didapatkan bahwa Dimensi Nasehat Merendahkan Diri Seperti Kristus ( D2 ) mampu memperbaiki sebesar 287.698 kali dari kondisi iImplementasi Pengajaran Paulus tentang Nasehat Hidup Bersatu Dan Merendahkan Diri Seperti Kristus Berdasarkan Filipi 2 : 1-30 Di Kalangan Gembala Sidang GPdI Se Jawa Tengah ( Y ) yang sekarang secara signifikan pada $\alpha<0,05$ sekaligus Dimensi Nasehat Merendahkan Diri Seperti Kristus ( D2 ) memiliki nilai importansi / sanggup mempengaruhi 100\% derajad distribusi perolehan skor Implementasi Pengajaran Paulus tentang Nasehat Hidup Bersatu Dan Merendahkan Diri Seperti Kristus Berdasarkan Filipi 2 : 1-30 Di Kalangan Gembala Sidang GPdI Se Jawa Tengah sebesar 361.208 . 
Independent Variable Importance

\begin{tabular}{l|c|c|}
$\begin{array}{l}\text { Independent } \\
\text { Variable }\end{array}$ & Importance & $\begin{array}{l}\text { Normalized } \\
\text { Importance }\end{array}$ \\
\hline $\begin{array}{l}\text { Nasehat } \\
\text { Merendahkan } \\
\text { Diri Seperti } \\
\text { Kristus }\end{array}$ & 361.208 & $100.0 \%$ \\
Nasehat Hidup & 342.683 & $94.9 \%$ \\
Bersatu & \\
Growing Method: CRT \\
Dependent Variable: Implementasi Pengajaran Paulus \\
tentang Nasehat Hidup Bersatu Dan Merendahkan Diri \\
Seperti Kristus Berdasarkan Filipi 2 : 1-30 Di Kalangan \\
Gembala Sidang GPdl Se Jawa Tengah
\end{tabular}

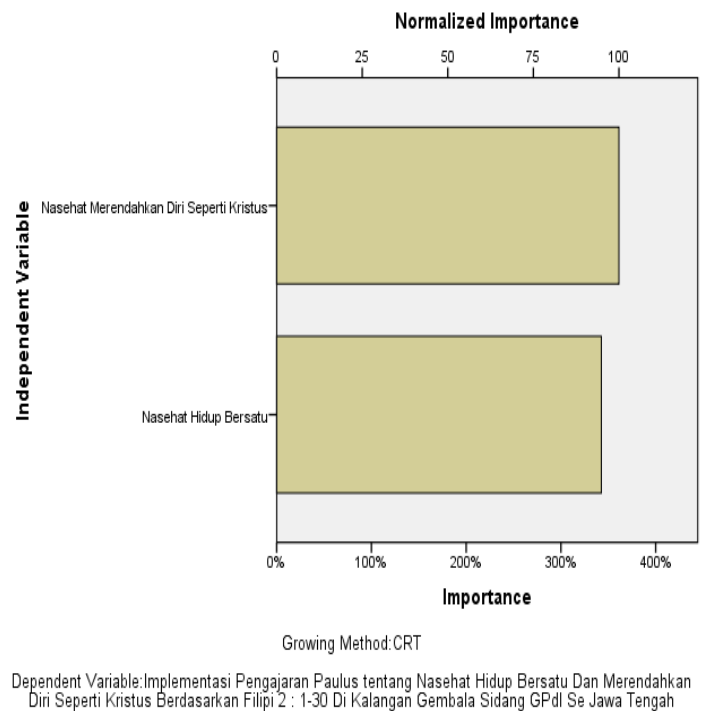

Sehingga dapat disimpulkan bahwa hipotesis kedua yang diajukan yaitu Dimensi yang paling dominan yang menentukan implementasi pengajaran rasul Paulus tentang nasehat untuk bersatu dan merendahkan diri seperti Kristus Berdasarkan Filipi 2:1 -30 di Kalangan Gembala - Gembala Sidang Gereja Pantekosta di Indonesia ( GPdI ) Se - Jawa Tengahadalah Nasehat merendahkan diri seperti Kristus (D2)dinyatakan diterima

Ketiga, pengujian atas hipotesis ketiga yaitu : Latar belakang responden yang paling menentukan implementasi pengajaran rasul Paulus tentang nasehat untuk bersatu dan merendahkan diri seperti Kristus berdasarkan Filipi $2: 1$-30 di kalangan gembala - gembala sidang Gereja Pantekosta di Indonesia ( GPdI ) Se - Jawa Tengah adalah Tingkat pendidikan. Dengan menggunakan analisa Klasifikasi dan regresi antara exogenous variable 
latar belakang sampel secara bersama - sama terhadap endogenous variable dengan menggunakan Classification and regression trees ( CRT ) pada taraf signifikansi 0,05 dengan maximum trees depth $=3$, minimum cases in parent node $=2$, dan minimum cases in child note $=1$. Untuk menguji kategori latar belakang mana yang paling mempengaruhi variabel $\mathrm{Y}$, dilakukan uji varian satu jalur ( One way anova ) pada taraf signifikansi 0,05. Dari hasil analisis antara exogenous variable latar belakang sampel secara bersama - sama terhadap endogenous variable yang menunjukan bahwa latar belakang Jumlah Jemaat ( L5 ) menjadi kategori latar belakang paling dominan membentuk Implementasi Pengajaran Paulus tentang Nasehat Hidup Bersatu Dan Merendahkan Diri Seperti Kristus Berdasarkan Filipi 2 : 1-30 Di Kalangan Gembala Sidang GPdI Se Jawa Tengah( Y ). Dari tabel Surrogates Latar belakang Jumlah Jemaat ( L5 ) mampu memperbaiki sebesar 9,740 kali dari kondisi Implementasi Pengajaran Paulus tentang Nasehat Hidup Bersatu Dan Merendahkan Diri Seperti Kristus Berdasarkan Filipi 2 : 1-30 Di Kalangan Gembala Sidang GPdI Se Jawa Tengah( Y ) yang sekarang secara signifikan pada $\alpha<0,05$ serta Latar belakang Jumlah Jemaat ( L5 ) memiliki nilai importansi / sanggup mempengaruhi $100 \%$ derajad distribusi perolehan skor Implementasi Pengajaran Paulus tentang Nasehat Hidup Bersatu Dan Merendahkan Diri Seperti Kristus Berdasarkan Filipi 2 : 1-30 Di Kalangan Gembala Sidang GPdI Se Jawa Tengah sebesar 9,740.

Independent Variable Importance

\begin{tabular}{l|r|r|}
\hline Independent Variable & Importance & $\begin{array}{r}\text { Normalized } \\
\text { Importance }\end{array}$ \\
\hline Jumlah_Jemaat & 9.740 & $100.0 \%$ \\
Pendidikan & 8.253 & $84.7 \%$ \\
Usia & 7.587 & $77.9 \%$ \\
Jenis_Kelamin & .714 & $7.3 \%$ \\
Status_Pernikahan & .016 & $0.2 \%$ \\
Growing Method: CRT & \\
Dependent Variable: Implementasi Pengajaran Paulus \\
tentang Nasehat Hidup Bersatu Dan Merendahkan Diri \\
Seperti Kristus Berdasarkan Filipi 2 : 1-30 Di Kalangan \\
Gembala Sidang GPdI Se Jawa Tengah
\end{tabular}




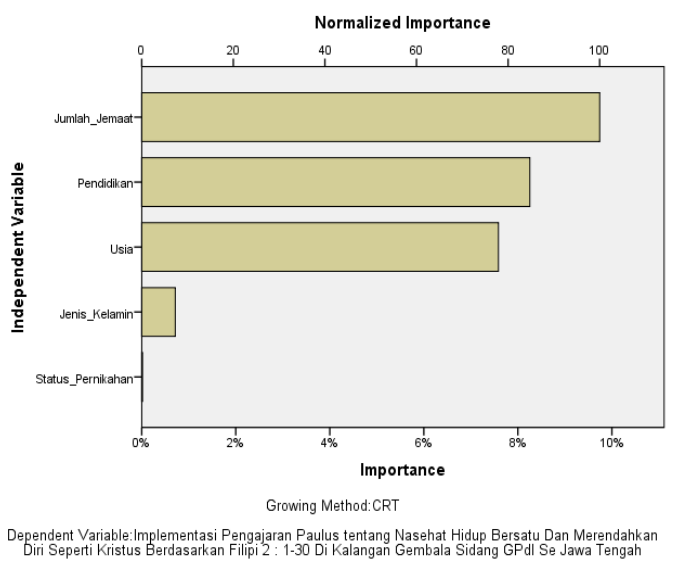

Dengan demikian dapat disimpulkan bahwa hipotesis ketiga yang diajukan Latar belakang responden yang paling menentukan implementasi pengajaran rasul Paulus tentang nasehat untuk bersatu dan merendahkan diri seperti Kristus berdasarkan Filipi 2 : 1 -30 di kalangan gembala - gembala sidang Gereja Pantekosta di Indonesia ( GPdI ) Se - Jawa Tengah adalah Tingkat pendidikan ternyata ditolak.

\section{REKOMENDASI PENGEMBANGAN PENELITIAN}

Penulis berharap hasil penelitian ini dapat bermanfaat bagi gereja, lembaga pendidikan dan terlebih kepada keluarga. Kiranya saran atau kritik dapat diberikan kepada penulis oleh semua pembaca agar dikesempatan selanjutnya penulis dapat lebih lagi dalam mengembangkan kemampuan yang telah diberikan oleh Tuhan. Penelitian ini masih dapat dikembangkan dengan melihat relevansi penelitian, dengan fakta-fakta di tahun-tahun selanjutnya, oleh orang-orang yang mau menguji atau mengembangkannya. Kemudian, penulis juga berharap kiranya penelitian ini dapat menjadi referensi dari penulis-penulis berikutnya yang sedang menulis tentang topik-topik seputar pembahasan yang ada pada artikel ini.

\section{KESIMPULAN DAN SARAN}

Bahwa untuk meningkatkan tingkat Implementasi Pengajaran Rasul Paulus Tentang Nasehat Untuk Bersatu Dan Merendahkan Diri Seperti Kristus Berdasarkan Filipi 2 : 1 -30 gembala - gembala Sidang Gereja Pantekosta Di Indonesia ( GPdI ) Se - Jawa Tengah harus bersinergi dalam membuat program - program yang inovatif dan efektif bagi kemajuan 
bersama bukan hanya untuk intern gereja masing - masing misal mengadakan pekan misi GPdI.

Selain itu untuk meningkatkan kontribusi setiap dimensi dari Pengajaran Rasul Paulus Tentang Nasehat Untuk Bersatu Dan Merendahkan Diri Seperti Kristus Berdasarkan Filipi 2 : 1 -30 perlu diadakan gathering / ramah tamah yang menumbuhkan kekompakan rasa bersatu dan saling memiliki antar gembala GPdI.

Sedangkan untuk meningkatkan kontribusi setiap latar belakang gembala dalam implementasi Pengajaran Rasul Paulus Tentang Nasehat Untuk Bersatu Dan Merendahkan Diri Seperti Kristus Berdasarkan Filipi 2 : 1 -30 perlu dibuat tim pelayanan diakonia MD yang dibagi ke setiap wilayah untuk dapat melayani di tempat - tempat pelayanan yang butuh dukungan terutama daerah - daerah gereja perintisan.

\section{BIODATA}

Dr. Esra Sitanggang adalah alumni mahasiswa doktoral di Sekolah Tinggi Teologi Kadesi Yogyakarta. Dia meneliti tentang nasihat hidup bersatu yang di ajarkan Paulus pada jemaat di Filipi. Jerih lelahnya mengkonversikan Disertasi ke artikel akhirnya selesai. Setiap bagianbagian dari tulisannya memiliki ciri khas tersendiri yakni sering menekankan sikap dan karakter yang berstandar Firman Tuhan.

\section{Esra Sitanggang}

Surel: sitanggangesral@gmail.com

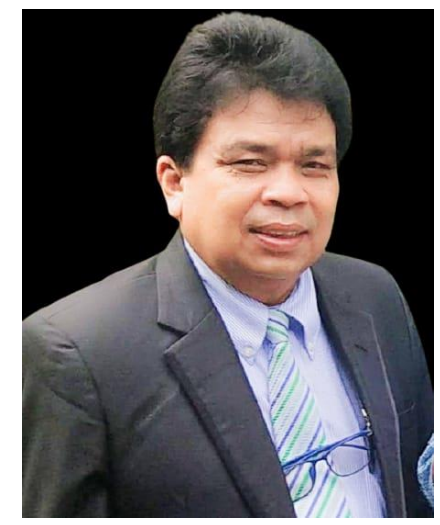

Dr. Muner Daliman, MA., M.Th., M.Pd.K adalah ketua Sekolah Tinggi Teologi Kadesi Yogyakarta. Dia mendapatkan visi misi yang besar dari Tuhan untuk mempersiapkan pemimpin dalam memimpin. Injil Kerajaan Sorga menjadi bagian yang utama, yang siap atau tidak siap, menurutnya harus diproklamirkan keseluruh dunia. Tulisan-tulisan yang telah ia buat selalu memiliki warna Kerajaan Sorga. Komitmen dan tekat yang kuat telah membuat Sekolah Tinggi Teologi Kadesi Yogyakarta dapat bersaing dengan

Sekolah Tinggi Lainnya.

\section{Muner Daliman}

Jl Turgo, Ngelosari, Puwobinangun, Pakem, Sleman, Yogyakarta.

Surel:munerdaliman@sttkadesiyogyakarta.ac.id 


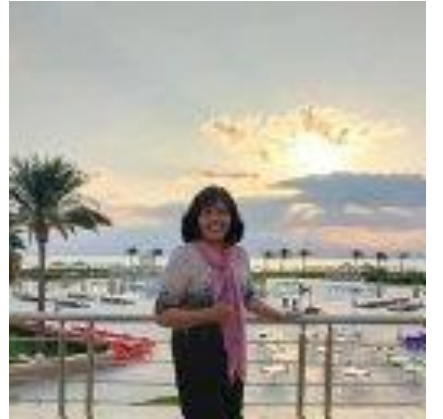

Dr. Hana Suparti, M.Th., M.Pd.K adalah direktur pascasarjana di Sekolah Tinggi Teologi Kadesi Yogyakarta. Dia cukup banyak menulis tentang etika yang didaratkan kesetiap situasi masa kini. Kepedulian dan keterbukaannya kepada mahasiswa dan kenalan yang lainnya memperlihatkan bahwa dia adalah sosok penulis yang suka berkerjasama.

\section{Hana Suparti}

Jl Turgo, Ngelosari, Puwobinangun, Pakem, Sleman, Yogyakarta.

Surel: hanasuparti@sttkadesiyogyakarta.ac.id

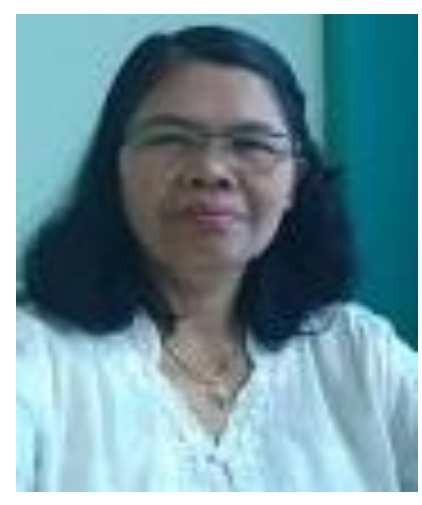

Dr. Sri Wahyuni adalah Waket 1 bidang akademik di Sekolah Tinggi Teologi Kadesi Yogyakarta. Kegigihannya dalam melakukan segala sesuatu membuat ia dipercakan untuk mengajar PAK Majemuk, Tafsir PB, dan Metodologi. Tulisan-tulisan yang ia buat lebih banyak menekankan konsep Kepemimpinan Hamba yang menurutnya konsep ini sangat relevan untuk diterapkan sepanjang jaman.

\section{Sri Wahyuni}

Jl Turgo, Ngelosari, Puwobinangun, Pakem, Sleman, Yogyakarta.

Surel: sriwahyuni@sttkadesiyogyakarta.ac.id

\section{DAFTAR PUSTAKA}

Chaniago, A. Y. S. (2002) 'Kamus lengkap bahasa Indonesia', Bandung: Pustaka Setia.

Charles Swindoll (2005) Improving Your Serve: The Art of Unselfish Living. Bandung: Pionir Jaya.

Creswell, J. W. (2015) Riset Pendidikan: Perencanaan, Pelaksanaan, dan Evaluasi Riset Kualitatif dan Kuantitatif, Yogyakarta: Pustaka Pelajar.

Duyverman, M. E. (1983) Pembimbing Ke Dalam Perjanjian Baru. Jakarta: lembaga penerbit kristen.

Ferdinand, A. (2011) 'Metode Penelitian Manajemen Pedoman Penelitian untuk Penulisan Skripsi Tesis dan disertai Ilmu Manajemen', Semarang: Universitas Diponegoro. 
Greenleaf, R. K. (2019) 'The Servant as Leader', in Leadership. doi: 10.2307/j.ctvpg85tk.36. Lexicon (no date) 'Bible Work 7'.

Marxen, W. (1996) Pengantar Perjanjian Baru: Pendekatan Kritis Terhadap Masalahmasalahnya. Jakarta: Gunung Mulia.

Roni, Y. (1993) Berbicara tentang Kesatuan Gereja. Yogyakarta: Andi.

Sidharta, L. (2019) “"Dari Kekosongan Kepada Kelimpahan”: Fondasi Trinitarian dari Spiritualitas Kristen', Veritas : Jurnal Teologi dan Pelayanan. doi: 10.36421/veritas.v12i2.243.

Thoha, M. (2007) Manajemen dan Kepemimpinan. Jakarta: Raja Grafindo Persada. Tingginehe, M. L. (2003) 'Membangun Gereja Secara Integratif-Ilahi-Insani Selaku Umat Allah-Tubuh Kristus-Bait Roh Kudus : Suatu Analisis terhadap Teologi O. E. Costas mengenai Pertumbuhan Holistik Gereja', Veritas : Jurnal Teologi dan Pelayanan. doi: 10.36421/veritas.v4i2.111.

Tomatala, Y. (2002) Kepemimpinan Yang Dinamis. Malang: Gandum mas.

Turangan, M. (2018) 'GPdI adalah sebuah gerakan di kalangan Protestanisme’, pp. 127-137.

Whitney, D. S. (1994) 10 Pilar Penopang Kehidupan Kristen. Bandung: lembaga Literatur Baptis.

Wijaya, D. A. (2019) 'Tinjauan Terhadap Teori Kenosis Menurut Filipi 2:6-8 dan Permasalahannya', Consilium, 20, pp. 153-171.

Wiliam Barclay (2002) Pemahaman Alkitab setia hari -Surat Filipi,Kolose, 1dan 2 Tesalonika. Jakarta: BPK Gunung Mulia.

Wiryoputro, S. (2008) Dasar Manajemen Kristiani. Jakarta: BPK Gunung Mulia. Zaluchu, S. E. (2010) 'Kepemimpinan Hamba [Servant Leadership]', in Tunaikan Tugas Pelayanan. 